\title{
Resenha do livro Uncovering Critical Personalism Readings from William Stern's Contributions to Scientific Psychology de James T. Lamiell
}

\author{
Review of the book Uncovering Critical Personalism Readings from \\ William Stern's Contributions to Scientific Psychology by James T. \\ Lamiell
}

\author{
Carolina de Resende Damas Cardoso \\ Universidade Federal de Catalão \\ Brasil
}

Em uma carta endereçada ao filósofo e amigo de longa data, Jonas Cohn (1869-1947), William Stern escreveu, em 1933:

\begin{abstract}
Eu espero que para além da satisfação em ver o livro acabado na sua frente, você terá uma satisfação ainda maior em constatar o impacto que este livro terá sobre pessoas aqui por perto ou distantes... porque o presente imediato não é exatamente favorável para trabalhos de tal natureza fundamental, que sem ser radical ou cheio de ilusões de grandeza, dirigem-se às questões mais decisivas da humanidade. Ainda assim, nós devemos ter a esperança de que esses tempos [propícios] retornarão, pois de outra forma, todos os nossos objetivos e realizações dos últimos 50 anos terão sido para nada! A História simplesmente não pode ser tão sem sentido! (Lück \& Löwisch, 1994, p. 166 citado por Lamiell, 2003, p. 20, grifos do autor, tradução nossa).
\end{abstract}

O livro referido neste trecho é o manual de Psicologia Geral (Allgemeine Psychologie auf personalistischer Grundlage [Psicologia Geral do ponto de vista personalístico]), que Stern começara a compor, mas que haveria de terminar apenas em 1938, ano de sua morte, nos Estados Unidos. Quem foi William Stern? Quais as "questões mais decisivas da humanidade" às quais ele se refere? $\mathrm{E}$, finalmente, qual a relevância de retomar esse personagem no panorama da psicologia atual?

Essas são algumas das perguntas que o livro Uncovering Critical Personalism readings from William Stern's contributions to Scientific Psychology, de James T. Lamiell busca responder. Radicado nos Estados Unidos e professor emérito da cadeira de Psicologia da Universidade de Georgetown (Washington, DC), Lamiell tem se dedicado ao estudo dos escritos de William Stern desde meados da década de 1980 , como nos relata no prefácio de sua obra. Interessante se faz notar que, 
após todos esses anos, pesquisador e objeto de seu estudo compartilham traços até mesmo em suas feições. Como nos relatou em sua autobiografia uma de suas mais notáveis alunas, Edith Stein, acerca de seu professor William Stern, "[...] seu rosto [era] rodeado por uma barba castanha; seus olhos eram inteligentes e bondosos, e a expressão de seu rosto e o som da sua voz eram sumamente doces e afáveis" (Stein, 2002, p. 306, tradução nossa). Poderíamos descrever Lamiell da mesma forma, bem como mencionar outras características partilhadas entre os autores, tais como o singular humanismo que os definem e as preocupações de ambos com o reducionismo epistemológico que ronda a psicologia - reducionismo este que será descrito mais adiante.

A proposta de Lamiell é trazer aos leitores alguns dos textos de William Stern concernentes à fundamentação da psicologia científica a partir do Personalismo Crítico. Este último é o sistema filosófico proposto por Stern, cujo âmago se configura na distinção entre pessoa e coisa, na definição de pessoa e na sustentação da psicologia científica a partir dessas definições. Trata-se, ademais, de uma crítica a uma psicologia mecanicista e atomista, que buscava seu status científico em conformidade com os moldes epistemológicos das ciências naturais, no final do século XIX e inícios do século XX. Lamiell (2021) nos apresenta a relevância desta proposta filosófica de Stern e questiona se a mesma tem lugar na psicologia atual.

Dos dez capítulos que compõem o livro Uncovering Critical Personalism..., sete capítulos e meio consistem nas traduções - feitas pelo próprio Lamiell - de alguns textos originais de Stern, em alemão, para a língua inglesa. Nesse sentido, seu objetivo principal é aproximar os leitores dos textos de Stern, tendo em vista a escassez das traduções das obras desse autor para a língua inglesa - e, pelo que consta, não há ainda traduções da obra de Stern para a língua portuguesa.

No primeiro capítulo do livro, intitulado William Stern and Personalistic Thinking: Making Acquaintance (William Stern e o pensamento personalista: fazendo uma apresentação, tradução livre), Lamiell nos apresenta a figura de William Stern, os aspectos relevantes de sua vida, de sua produção e do contexto que favoreceu a criação do Personalismo Crítico. Os capítulos dois ao nove (com exceção do sexto) tratam de uma breve explanação introdutória, seguida da tradução de alguns textos de Stern publicados entre os anos de 1906 e 1933. Respectivamente, os capítulos são intitulados: Impersonalism (Impersonalismo, tradução livre), The Concept of the Person and The Problem of Freedom ( $\mathrm{O}$ conceito de pessoa e o problema da liberdade, tradução livre), Personalistic Psychology (Psicologia Personalista, tradução livre), The Personalistics of Recollection (A personalística da recordação, tradução livre), Personality Research 
and the Methods of Testing (Pesquisa sobre personalidade e métodos de testagem, tradução livre), The Personal Factor of Psychotechnics (O fator pessoal da psicotécnica, tradução livre), Meaning and Interpretation (Sentido e interpretação, tradução livre).

A primeira metade do capítulo sexto, intitulado The 'Problem of Individuality' in Scientific Psychology (O 'problema da individualidade' na psicologia científica, tradução livre), conta com escritos do próprio Lamiell, seguido da tradução de um texto de Stern publicado em 1911 (Capítulo 21 da obra Methodological Foundations of Differential Psychology). Por fim, no décimo capítulo do livro, Lamiell busca analisar as razões pelas quais o sistema filosófico de Stern fora ignorado até o presente momento pela psicologia.

Ademais, podemos destacar outras valiosas obras de Lamiell que discorrem sobre as contribuições de William Stern à psicologia científica, tais como 'Beyond individual and group differences: human individuality, scientific psychology, and William Stern's Critical Personalism' (2003); 'William Stern (1871-1938): a brief introduction to his life and work' (2010); 'Psychology's misuse of statistics and persistent dismissal of its critics' (2019), dentre outras.

O pesquisador, no presente livro resenhado, se dedica a discutir as questões colocadas anteriormente, sendo a primeira delas, quem foi William Stern? Como bem descrito por Helmut E. Lück no prólogo, Stern já é um "velho conhecido" da psicologia, porém, seu conhecimento é deveras "compartimentalizado" (Lamiell, 2021, p. viii, tradução nossa). Psicólogos experimentais, pesquisadores da psicologia aplicada, ou da área do psicodiagnóstico, psicologia forense, psicologia da personalidade e do desenvolvimento, reconhecem em Stern algum aspecto de suas respectivas áreas. Por exemplo, como psicólogo experimental, Stern debruçara-se sobre o estudo da apercepção da mudança; na área da psicologia da personalidade, foi o proponente da chamada Psicologia Diferencial; na área da psicologia aplicada, cunhou, em 1903, o termo "Psicotécnica", bem como, em 1912, criou o termo "Quoeficiente de Inteligência", medida para os estudos da psicologia da infância. No Brasil, Stern é mais conhecido (e criticado) pelo último.

De especial relevância para a área da psicologia da infância, podemos destacar o extensivo trabalho de William Stern, em colaboração com sua esposa, Clara Stern (1877-1945), acerca do desenvolvimento infantil. A senhora Stern mantinha diários onde descrevia os aspectos do desenvolvimento dos três filhos do casal, nascidos, respectivamente, em 1900, 1902 e 1904. Tais diários somam milhares de páginas contendo as observações do casal desde a gestação até os 18 anos dos filhos. A partir dessas observações, foram publicados dois volumes acerca do desenvolvimento psicológico das crianças (seelische Entwicklung des Kindes), 
o primeiro intitulado 'A linguagem infantil: uma investigação psicológica e linguística' (1907) e o segundo, 'Memória, testemunho e mentira na primeira infância' (1909). Outra importante obra, também baseada nos diários, foi publicada em 1914 (em sua primeira edição), 'Psicologia da primeira infância aos seis anos de idade'.

Como nos relata em sua autobiografia, William Stern (1930) nunca desejara ser reconhecido apenas como o propositor do "dourado termo médio" (Stein, 2002, p. 309, tradução nossa), ou "QI". De qualquer forma, ainda que embrenhado em inúmeros trabalhos e pesquisas empíricas em psicologia experimental e pedagogia, Stern definiu como o ofício de sua vida, a busca e o estabelecimento de uma Weltanschauung (visão de mundo).

De origem judaica, Louis William Stern nasceu em Berlim, no dia 29 de abril de 1871. Em 1888, ingressou na Universidade de Friedrich-Wilhelm (Berlim) para estudar filologia e filosofia. Eventualmente, abandonou o curso de filologia e se dedicou à psicologia, então subárea da filosofia. Em suas pesquisas, Stern seguia uma linha empírica para a abordagem das questões psicológicas, orientado, principalmente, pelo trabalho de Gustav Fechner (1801-1887) em Psicofísica e de Wilhelm Wundt (1832-1920). Ainda na faculdade, também foi fortemente influenciado pela psicologia experimental de Hermann Ebbinghaus (1850-1909). (Stern, 1930).

Como psicólogo experimental e professor da Universidade de Breslau, foi um dos fundadores da Associação Psicológica daquela cidade, assumindo sua presidência. Foi devido às iniciativas de Stern que esta associação se tornou, junto à de Berlim e Munique, a Sociedade Alemã para Pesquisa Psicológica e, posteriormente, o centro da Sociedade de Psicologia Experimental, fundada em 1904. Vinte e cinco anos mais tarde, essa última se tornaria a Associação Psicológica Alemã (Hardesty, 1976). Entretanto, como o próprio autor nos aponta em sua autobiografia, Stern não se contentava com a separação entre a filosofia e a psicologia científica. Tal separação, para ele, representava um sério reducionismo àquela ciência que almejava o estudo dos processos mentais (Stern, 1930).

Sua Weltanschauung, como nos relata, encontrava-se já em estado embrionário em seus anos como estudante. Desde essa época, trabalhando com psicologia experimental, ele já intuíra o declínio de uma psicologia que assumia de forma acrítica os parâmetros das ciências naturais, em especial, o mecanicismo e atomismo presentes naquela ciência que ganhava sua independência da filosofia. Stern buscava, portanto, uma Weltanschauung que compreendesse um retorno à metafísica como disciplina que orientasse a vida e as produções filosóficas e 
científicas (Stern, 1930). Podemos ilustrar sua posição ainda com outro trecho de uma correspondência a Jonas Cohn, datada de 11 de novembro de 1900, na qual apontara:

\begin{abstract}
Estou começando a ler o novo trabalho ${ }^{1}$ de Münsterberg ${ }^{2}$ que eu devo revisar para Ebbinghaus. Simpatizo-me com a seriedade e urgências com as quais Münsterberg considera questões e princípios filosóficos. Ele é melhor que sua reputação. Contudo, a solução que aponta não me satisfaz. Ele nos deixa ainda com o problema de reconciliar as "duas verdades" [filosófica e científica]. Não podemos ser sem contradição, um idealista ético na metafísica e, ao mesmo tempo, um mecanicista na psicologia (Lück \& Löwisch, 1994, p. 39 citado por Lamiell, 2003, p. 40, tradução nossa).
\end{abstract}

Ainda na mesma esteira, Lamiell (2021) nos aponta que não é coincidência que o ano de 1900, ano do nascimento de sua primeira filha, Hilde, foi também o ponto de partida para o início do desenvolvimento de seu sistema filosófico, o Personalismo Crítico, por sua vez, contemplado em sua Weltanschauung. Em suas próprias palavras, Stern (1930) nos descreve:

Aqui [quando do nascimento de sua filha], tomei consciência do fato personalista fundamental da unitas multiplex: a riqueza dos fenômenos, concomitante ou sucessivamente observáveis, organizou-se em uma linha de vida unificada do indivíduo em desenvolvimento e recebeu seu significado diretamente disso.... Aqui ganhei fundamentos conceituais para a teoria filosófica nascente (pp. 350-351, tradução nossa).

A Weltanschauung que Stern propõe admite uma reformulação dos problemas filosóficos esboçados a partir da Idade Moderna, com a cisão promovida por René Descartes (1596-1650) entre alma (psique) e corpo (natureza). Para o autor, "a necessidade de uma orientação filosófica apareceu-me não somente como um desejo [próprio] subjetivo, mas como uma desesperada necessidade daquele tempo" (Stern, 1930, p. 352, tradução nossa).

Stern se referia, a essa altura, às concepções epistemológicas que sugeriam cada vez mais uma separação não apenas entre a psicologia científica e a filosofia, mas também em relação ao próprio objeto estudado por essa ciência, cuja consideração se via às voltas da atomização, ou seja, da fragmentação do objeto inteiro em suas partes constitutivas menores, por um lado; e da afirmação de uma unidade abstrata sustentada por leis causais expressas matematicamente, por outro. Em suas palavras, no primeiro caso, "a heterogeneidade em retalhos parecia destruir toda possibilidade de unidade; no segundo, a falácia da [busca por uma]

\footnotetext{
1 Refere-se à obra Fundamentos da Psicologia, publicada em 1900.

2 Hugo Münsterberg (1863-1916), renomado psicólogo experimental do início do século XX.
} 
simplificação excessiva privava a realidade de sua totalidade; ciência e vida eram ou divididas ou esvaziadas de seus conteúdos" (Stern, 1930, p. 352, tradução nossa).

Mal sabia o autor, que escrevera sobre "uma desesperada necessidade daquele tempo", que apenas alguns anos mais tarde, em 1933, com a ascensão do Partido Nazista ao poder, iniciar-se-ia uma perseguição mais acirrada aos judeus nos territórios alemães. A mecanização, o tecnicismo, a atomização e a despersonalização dos indivíduos extrapolariam os limites da ciência e estenderiam seus braços na própria vida social. A partir de então, a vida pessoal de Stern fora marcada por muitas perdas. Por ser ele próprio judeu, fora demitido da Universidade de Hamburgo que anos antes havia ajudado a fundar; fora afastado de suas diversificadas atividades profissionais. Viu seus amigos e colegas que não eram judeus serem perseguidos pela proximidade que tinham com ele, dois deles acabaram por cometer suicídio, Otto Lipmann (1880-1933) e Martha Muchow (1892-1933). Com relutância, Stern emigrou aos Estados Unidos com sua esposa. Passou seus últimos anos como professor na Universidade de Duke e faleceu em 1938.

\section{O Personalismo Crítico}

Interessante se faz notar como a vida de Stern e seu sistema filosófico estão entranhados, ainda que de forma não imediatamente intencional. Stern não compreendia a irracionalidade daquele tempo em que vivia e, à princípio, acreditava no retorno à Razão de seus compatriotas (como nos recorda Ringer (2000) acerca dos chamados "mandarins alemães", ou intelectuais do século XIX, que afirmavam a superioridade do Geist alemão, ou seja, da mentalidade a respeito do valor estabelecido de uma supremacia do exercício racional em detrimento à "superficialidade e vulgaridade" do mero pragmatismo científico). Sabemos que essa esperança, infelizmente, não fora concretizada no período de sua vida.

O seu sistema apregoava o retorno da Metafísica - não de uma metafísica "ingênua", mas um sistema filosófico crítico - que contemplasse "[...] não as causas da realidade, mas o seu significado" (Stern, 1930, p. 352, tradução nossa). E ainda, ele esclareceu que por metafísica, queria dizer "não a posse completa da verdade, mas uma fé na busca do ser e do valor; eu creio num mundo que ao mesmo tempo existe e é portador de valor; e eu busco esse mundo" (Stern, 1930, p. 368, tradução nossa). 
Stern colocou no âmago de sua Weltanschauung, a concepção de pessoa. A premissa básica desse sistema, nas palavras de Stern, é sustentar que "a cosmologia, a ciência e a vida devem ter suas raízes na metafísica, e que a categoria fundamental para o tempo presente e o próximo dever ser àquela da 'pessoa'" (Stern, 1930, p. 368, tradução nossa). Também no âmago de sua proposta, destacou o premente desafio da distinção entre pessoa e coisa.

Para Stern, a definição de pessoa engloba também o sujeito humano consciente, mas não apenas. "[A pessoa] é um ser existente tal que apesar da pluralidade de suas partes, constitui uma unidade real, única, dotada de um valor próprio e, [...] apesar da pluralidade das funções de suas partes, realiza uma atividade própria unitária e [com uma finalidade] determinada" (Stern, 1906, citado por Lamiell, 2021, p. 6, tradução nossa). Ele enquadra a pessoa nos termos de uma unitas multiplex, devido a essa constituição plural e, no entanto, unitária. Isso significa que 'pessoa' qualifica todo ser existente que, mesmo constituído por inúmeras "partes", constitui uma unidade - para além das mesmas partes - que é dotada de um valor próprio, além de ter a sua existência voltada a alguma meta (e, com isso, Stern afirma o sentido teleológico de toda existência pessoal).

Segundo Stern, o termo 'pessoa' não se identifica nem com a substância material (por exemplo, com o corpo) e nem com a anímica (psique ou espírito) e nem mesmo com a consciência. Denota, ao contrário, um âmbito próprio do ser que é ontologicamente neutro. A pessoa humana, por sua vez, é definida como "[uma] personalidade viva, unitária, total, que em todas as incontáveis relações de meta [goal] com o mundo exterior, bem como na plenitude dos fenômenos das experiências interiores, preserva sua unidade" (Stern, 1906, citado por Lamiell, 2021, p. 47, tradução e grifos nossos).

O seu postulado fundamental não se encerra, contudo, nesta definição, mas conta com o esclarecimento daquele nível da existência que se encontra no polo oposto, ou seja, o nível impessoal, o das 'coisas'.

Consideramos como "coisas" todas as entidades que não são entendidas como totalidades individuais autoativadas. Uma 'coisa' é, portanto, uma entidade que é um conglomerado, mas não uma unidade; passiva e não autoativável, e é, com relação a outras entidades, comparável, mensurável e intercambiável, em vez de individual e única. Com "coisas", as ocorrências não resultam das ações das próprias coisas, mas são provocadas causalmente por meio do funcionamento de leis gerais que são externas a essas coisas. O funcionamento das coisas é cego e mecânico. As coisas não têm objetivos próprios e podem, na melhor das hipóteses, ser úteis para a realização dos objetivos de alguma outra entidade 
(Stern, 1906, citado por Lamiell, 2021, p. 50, tradução e grifos nossos).

A conclusão de Stern é que os aspectos impessoais das coisas são, na verdade, constituintes da totalidade do Ser pessoal - ou partes dele. Com essa asserção, ele acredita ter ultrapassado o antigo dualismo entre matéria e espírito (ou corpo e mente), afirmando a constituição teleomecânica das relações entre o todo e as partes, além da neutralidade psicofísica do Ser - ou seja, o termo pessoa não denota uma realidade física e nem psíquica, mas reafirma o seu ser próprio.

Em síntese, a pessoa se encontra no âmago do sistema filosófico e Weltanschauung de William Stern. Essa proposta é dada em resposta às referidas "questões urgentes do nosso tempo". O autor (Stern, 1906, citado por Lamiell, 2021, p. 43) se referia ao que ele denominou de "época coisal" na qual ocorria uma despersonificação em massa da ciência, mas também da cultura e da vida. 0 impessoalismo, refletido principalmente pelo positivismo e pelas decorrentes doutrinas naturalistas e materialistas da época, representava, para o autor, um fechamento da realidade, um empobrecimento da mesma e, até mesmo, uma violência, pois omitia (ou era indiferente a) diversos aspectos importantes, como o reconhecimento da existência do mundo dos valores reais. O Personalismo Crítico, admitidamente, se colocou como uma alternativa que buscava superar postulados do positivismo e do materialismo, da coisificação da natureza e do espírito.

Com o Personalismo Crítico, Stern pretendeu se acercar de um duplo propósito: o primeiro, de estabelecer seu sistema filosófico como uma nova metafísica que abrangesse uma nova teoria do conhecimento (de oposição ao positivismo e às filosofias modernas da consciência); o segundo, propô-lo como base para uma nova prática científica, capaz de fornecer fundamentos à psicologia, mas também às ciências humanas.

\section{A retomada do Personalismo Crítico para a Psicologia atual}

Apesar de ter seu trabalho amplamente reconhecido em vida, após sua morte, a proposta de William Stern de uma psicologia fundada no Personalismo Crítico fora ofuscada. Nas palavras de Lamiell (2021, p. 187, tradução nossa), "[...] muito poucos psicólogos do século XXI tiveram a oportunidade de considerar como poderia ser uma psicologia personalista [de acordo com] o patrimônio intelectual de Stern. [Por essa razão] O objetivo principal do presente volume é ajudar a preencher essa lacuna na literatura disciplinar". 
Lamiell lista as principais razões pelas quais acredita que ainda não há espaço para o sistema de Stern na psicologia atual. São as seguintes:

(1) o uso [que a psicologia faz] persistente e de longa data de métodos estatísticos agregados como base para reivindicações de conhecimento científico sobre os indivíduos, (2) o apelo acrítico a entendimentos duvidosos de medição, (3) a confiança contínua em testes de significância de hipótese nula como um meio de fazer avançar a teoria psicológica e (4) a dicotomização nítida dos métodos de pesquisa qualitativa e quantitativa (Lamiell, 2021, pp.187-188, tradução nossa).

Esses pontos citados pelo autor nos remetem a um contexto em que a psicologia não se tornou independente ainda dos pressupostos de uma epistemologia positivista, ainda que Lamiell se refira basicamente ao contexto estadunidense. Resta, então, a questão de se o mesmo (a desconsideração ou a desvalorização de um trabalho conceitual, de natureza filosófica, em primeiro lugar) ocorre também por aqui, nos trópicos - ou no contexto da psicologia latinoamericana. É possível que no Brasil haja, sim, mais espaço para trabalhos dessa natureza. Havemos de lembrar, contudo, as limitações da linguagem, tendo em vista a falta de traduções das obras de William Stern à língua portuguesa. Nesse sentido, as traduções que estão disponíveis em inglês, principalmente devido ao trabalho incansável de Lamiell, são auxílios importantes no despertar de novo interesse e novas pesquisas sobre Stern.

Cabe-nos retomar, a essa altura, que William Stern buscou sustentar a sua proposta de psicologia em um alicerce filosófico do Personalismo. Segundo o autor, sem este fundamento filosófico, a psicologia correria o risco de perder a sua própria razão de ser. Em suas palavras (Stern, 1935, p. 10, citado por Lamiell, 2021, p. 191, tradução e grifos nossos):

[...] uma relação simbiótica entre considerações filosóficas e descobertas metodológicas é inevitavelmente necessária. A convicção, ainda hoje difundida, de que a psicologia poderia ou deveria se tornar uma disciplina totalmente independente da filosofia, leva ou a uma psicologia sem psique ou a um trabalho científico que incorpora uma visão de mundo e sustenta pressupostos epistemológicos que não são conscientemente reconhecidos [pelo psicólogo]".

As palavras de William Stern ecoam também hoje como verdadeiras. Acrescentaríamos ainda outro reducionismo (que vem ganhando destaque no contexto brasileiro) atualmente a rondar a psicologia, qual seja, a própria negação do conceito de pessoa e as perdas que esta implica - em última instância, a 
transformação de pessoas em coisas, ou seja, a despersonificação da existência humana. É nesse sentido que a retomada da proposta de William Stern no contexto atual da psicologia pode contribuir sobremaneira para lançar luzes à fundamentação filosófica e epistemológica da psicologia atual.

\section{Referências}

Hardesty, F. P. (1976). Louis William Stern: a new view of the Hamburg years. Psychology in progress. Em Annals of the New York Academy of sciences, v. 270. New York: New York Academy of Sciences.

Lamiell, J. T. (2003). Beyond individual and group differences. Human individuality, scientific psychology and William Stern's Critical Personalism. Thousand Oaks, EUA: SAGE Publications.

Lamiell, J. T. (2010). William Stern (1871-1938): a brief introduction to his life and works. Lengerich, Alemanha: Papst Science Publishers.

Lamiell, J. T. (2019). Psychology's misuse of statistics and persistent dismissal of its critics. Cham, Suíça: Palgrave Macmillan.

Lamiell, J. T. (2021). Uncovering Critical Personalism readings from William Stern's contributions to scientific psychology. Cham, Suíça: Palgrave Macmillan.

Ringer, Fritz K. (2000). O declínio dos mandarins alemães - a comunidade acadêmica alemã, 1890-1933 (D. A. Azevedo, Trad.). São Paulo: Edusp. (Original publicado em 1969).

Stein, E. (2002). Vida de una familia judía. Em E. Stein. Escritos autobiográficos y cartas. Vol. I (J. G. Rojo e cols., Trad.). Burgos: Editorial Monte Carmelo; Vitoria: Ediciones El Carmen; Madrid: Editorial de Espiritualidad (Originais de 1933 e 1939, publicação póstuma em 1964).

Stern, W. (1930). Autobiography. Em C. Murchison (Ed.). A History of Psychology in autobiography. Vol 1 (pp. 335-388). Worcester, Massachusetts: Clark University Press. (Original publicado em 1927).

\section{Nota sobre a autora:}

Carolina de Resende Damas Cardoso é graduada em Psicologia pela Universidade Federal de Uberlândia. Mestre e Doutora em Psicologia pela Faculdade de Filosofia, Ciências e Letras, da Universidade de São Paulo - Ribeirão 
Preto. Psicóloga na Universidade Federal de Catalão, Goiás. E-mail: cmrdc@hotmail.com.

Data de submissão: 04.10 .2021

Data de aceite: 06.11 .2021 